
\title{
25 Research Soure \\ Factors Associated With Prolonged Hospital Stay: a Retrospective Study for Imported Malaria Cases
}

\section{Liang Huang}

Chengdu Public Health Clinical Center https://orcid.org/0000-0002-9607-7939

\section{Hong Jin}

Chengdu Public Health Clinical Center

\section{Hong Zhang}

Chengdu Public Health Clinical Center

\section{Yang Liu}

Sichuan Center for Disease Control and Prevention

\section{Xinxing Shi}

Chengdu Public Health Clinical Center

\section{Xintong Kang}

Chengdu Public Health Clinical Center

\section{Yilan Zeng}

Chengdu Public Health Clinical Center

Lin Wang (D15201920@qq.com)

Chengdu Public Health Clinical Center

\section{Research Article}

Keywords: Malaria, Prolonged hospital stay, Imported cases

Posted Date: May 4th, 2021

DOI: https://doi.org/10.21203/rs.3.rs-447805/v1

License: (c) (1) This work is licensed under a Creative Commons Attribution 4.0 International License. Read Full License 


\section{Abstract}

\section{Background}

China had entered post-elimination era for malaria, however, the imported cases are continuously are a public health concern as the increasing number of cases. In this study we studied the potential predictive factors for prolonged hospital stay for imported malaria patients.

\section{Material and Methods}

We retrospectively collected patients of imported malaria cases data from 2017-2020 in our hospital. we analyzed the data from clinical, epidemiological, geographical, and seasonal points of view, and used cox proportional hazard model to find the predictive factors for prolonged hospital stay.

\section{Results}

We found most of imported cases were from Democratic Republic of the Congo(23\%, 34/150) and most cases $74 \%(26 / 34)$ were infected by $P$. falciparum. Through Edwards Test, no significant seasonality of imported cases were found $(x 2=2.51 p$-value $=0.28)$. We found bacterial infection( $H R=0.58, p$-value $=0.01)$ and thrombocytopenia(HR=0.66, $\mathrm{p}$-value $=0.02)$ were protective factors for discharge, that were, the risk factors for prolonged hospital stay.

\section{Conclusions}

The imported cases are the major risk of malaria in post-elimination era of China. The bacterial infection and thrombocytopenia were the risk factors for prolonged hospital stay.

\section{Background}

Due to the implementation of National Malaria Elimination Program (NMEP) carried out in $2010^{1}$, China had reported final indigenous case of malaria in 2015 from Canyuan County, Yunnan Province ${ }^{2}$. Zero indigenous case had been achieved in $2017^{3}$ after three consecutive years of zero case reporting, fulfilled the criteria of $\mathrm{WHO}^{4}$. China has entered the era of post-elimination, all the malaria cases were imported from oversea. Most of them were exported labour to Africa, the steadily increasing number of imported patients has been has been imposing great public risk to China society ${ }^{5,6}$.

Our hospital located in Chengdu City, which is the provincial capital of Sichuan province(Western China, including eastern Qinghai-Tibet Plateau), is the only tertiary hospital for infectious disease in Chengdu City. It is providing services for Chengdu city and most area of the Sichuan province. It hospitalized majority cases of malaria imported into Sichuan provinces. In 2019, our hospital passed the national examinations for NMEP, qualified for malaria patients managements, diseases reporting, treatments, diagnosis, laboratory things, and staff training. So that the dataset of malaria from our hospital could be a representative subset for imported patients in China. 
Treatments for malaria would be successful and effective if appropriate intervenes engaged in time ${ }^{7,8}$. However, according to our experience, the clinical conditions and length of stays(LOSs) for patients varied in a wide range. In this study, we focused on investigation of the predictive factors for prolonged hospital stay, give the evidence for clinical decisions and patients managements. No previous study had covered this topic for imported malaria cases in China.

\section{Material And Methods}

\section{Patients}

We retrospectively collected malaria cases for Hospital information System(HIS) from 2017 to 2020. Totally 150 cases we retrieved, we collected clinical descriptions including medical history, main complains, sources of countries, et al. The laboratory tests results including blood routine, liver function, and medical images records.

The written forms of agreements were signed by patients before admissions. Ethical approval for this study was obtained from the Ethics Committee of the Chengdu Public Health Clinical Center. The patient consents for inclusion was waived as the retrospective nature of this study.

\section{Criteria}

All patients confirmed by pathogenic evidence of plasmodium. Patients with suspected malaria, however, excluded by later medical investigation were excluded from this study. The diagnosis was followed with national recommendation for malaria diagnose(WS 259-2015) ${ }^{9}$.

For the criteria of discharge, we routinely followed by rules of our hospital as below: 1 . No plasmodium was found in blood by microscopy. 2. Significant improvement of clinical signs, manifestations, and laboratory examinations 3 . Normal body temperature for more than 3 Days.

\section{Statistical analysis}

The statistical analysis was performed with the STATA/SE 14.1 software (StataCorp,4905 Lakeway Drive, College Station, Texas, USA) and R 4.0.2 ${ }^{10}$. SEAST module for STATA was installed for Edwards seasonality test ${ }^{11}$. The networkD3 for $\mathrm{R}$ was used for diagram plotting ${ }^{12}$.

The continuous data were presented as mean with standard deviations for normal distribution or median with range for other distribution. Multivariable cox proportional hazard regression with stepwise variables selection were used for fitting the data. The Edwards Test for seasonality was used for time series data of cases number ${ }^{11}$. Log-rank was used for testing equality of survivor functions. The a was set to 0.05 . $P<a$ was considered to be statistically significant.

\section{Results}




\section{General characteristics of patients}

All the patients were Chinese nationalities, they all infected malaria out of China. All of them were exported labor services for Africa or two Asian countries(Myanmar and Pakistan). All of the were male, with the median age of 42 years(range from 19 to 62 ) old. All of them have a healthy background, since they had passed body examinations for being a exported labour before going abroad(Table 1 ).

Table 1

General characteristics of patients

\begin{tabular}{|lll|}
\hline Variables & Mean/Median/\% & SD/Range \\
\hline Age(years) & 40.18 & 11.01 \\
\hline Days of Fever before admission(Days) & 7 & $0.2-30$ \\
\hline Previous infection times(times) & 1 & $1-11$ \\
\hline Infection rate & $0.2 \%$ & $0 \%-15 \%$ \\
\hline Bacterial infection rate & $20 \%$ & - \\
\hline Length of stay(Days) & 7 & $3-23$ \\
\hline ALT(U/L) & 38 & $7-199$ \\
\hline AST(U/L) & 38 & $14-235$ \\
\hline TBIL $(\mu \mathrm{mol} / \mathrm{L})$ & 19.60 & $5-334.7$ \\
\hline WBC $\left(10^{9} / \mathrm{L}\right)$ & 5.43 & $1.58-11.15$ \\
\hline $\operatorname{PLT}\left(10^{9} / \mathrm{L}\right)$ & 84 & $10-624$ \\
\hline HGB $(\mathrm{g} / \mathrm{L})$ & 135 & $77-177$ \\
\hline ALB $(\mathrm{g} / \mathrm{L})$ & 37.95 & $21.6-50.6$ \\
\hline Creatinine $(\mu \mathrm{mol} / \mathrm{L})$ & 72 & $32.8-230$ \\
\hline $\mathrm{CRP}(\mathrm{mg} / \mathrm{L})$ & 58.42 & $0.5-281.2$ \\
\hline
\end{tabular}

\section{Clinical signs distributions}

Fever is the major manifestation of malaria, $99 \%(149 / 150)$ cases had reported fever with difference length of durations(Median $=3$ days, range from 1 to 30 days). $83 \%$ cases had reported shiver while abnormal body temperatures were presenting. 46\% (69/150)cases suffered headache, which was the third most common manifestation of malaria cases. $19 \%(28 / 150)$ cases had reported cough, $54 \%(15 / 28)$ of them were productive cough. Other clinical signs including fatigue $(44 \%, 66 / 150)$, anorexia( $17 \%$, 26/150), and muscular soreness(15\%, 22/150). 


\section{Medical history distributions of the patients}

In the Hospital Information System(HIS), we recorded the detail of the onset and medical history, and history of current illness. Half of them $(50 \%, 75 / 150)$ had been infected by plasmodium for more than once, $68 \%$ cases were infected by plasmodium for more than twice.

Of note, $17 \%(25 / 150)$ cases had reported misdiagnosed by other medical facilities, since the malaria lack of specific clinical signs, many doctors in non-history-endemic area had no experience for diagnosis.

To investigate if there was any delay for diagnosis for any reason, we recorded the days from onset of fever before came to our hospital(DOF). The DOFs were range from 0.2-30 days(DOFs may include the days before custom entry) with the median of 3 days.

\section{Geographical and pathogens distributions}

Excepted one case came back from Myanmar diagnosed with $P$. vivax infection, three cases came back from Pakistan infected by $P$. vivax, other cases were from Africa. Most of the cases were infected or coinfected by $P$. falciparum, the proportions were $74 \%(111 / 150)$ and $\% 4(6 / 150)$ respectively. The second most common infection were caused by $P$. vivax. The infection and co-infection proportion were $16 \%$ $(24 / 150)$ and $3 \%(4 / 150)$ respectively.

Geographically, most of imported cases were from Democratic Republic of the Congo, the proportion is $23 \%(34 / 150), 74 \%(26 / 34)$ cases were infected by $P$. falciparum. The second most cases were from Equatorial Guinea, the proportion was $14 \%(21 / 150), 81 \%(17 / 21)$ of them were infected by $P$. falciparum(Table 2,3). A Sankey diagram was used for describe the relationship between source of countries and pathogens(Fig. 1).

Table 2

Pathogen distributions

\begin{tabular}{|ll|}
\hline Pathogens & Number of patients \\
\hline P. falciparum & 111 \\
\hline P. ovale & 4 \\
\hline P. vivax & 24 \\
\hline P. falciparum + P. ovale* & 3 \\
\hline P. malariae & 4 \\
\hline P. falciparum + P. vivax & 3 \\
\hline P. ovale +P. vivax & 1 \\
\hline * Co-infections & \\
\hline
\end{tabular}


Table 3

Countries distribution of patients

\begin{tabular}{|ll|}
\hline Countries & Numbers of patients \\
\hline Nigeria & 13 \\
\hline DRC $^{*}$ & 34 \\
\hline Pakistan & 3 \\
\hline Equatorial Guinea & 21 \\
\hline Myanmar & 1 \\
\hline Zimbabwe & 5 \\
\hline Mozambique & 1 \\
\hline Ivory Coast & 12 \\
\hline Uganda & 6 \\
\hline Guinea & 1 \\
\hline Cameroon & 18 \\
\hline Chad & 3 \\
\hline Ethiopia & 9 \\
\hline Ghana & 5 \\
\hline Bangui & 1 \\
\hline Sudan & 1 \\
\hline Angola & 10 \\
\hline Benin & 2 \\
\hline Gabon & 2 \\
\hline Sierra Leone & 2 \\
\hline * Democratic Republic of the Congo \\
\hline
\end{tabular}

\section{Time distribution of cases}

We overlapped the variations of cases for the four years in to one chart. We can figured out no significant peaks were found. The decreasing of 2020 were due to the due to the polices of quarantine for Covid- 19 . 
To understand if the samples from our hospital has the seasonality. We used Edwards Test for seasonality ${ }^{11}$. The $\chi^{2}=2.51 p$-value $=0.28$. This result rejected the significant seasonality of the cases admission time distribution from the point of statistical view (Fig. 2).

\section{Laboratory tests of the patients}

According to our regulations, all the patients of malaria were undergone emergency medical evaluations regardless the clinical condition and potential prognosis. The assessment included blood routine, blood biochemical tests, plasmodium and $\mathrm{RDT}^{13}$, X-ray or CT scan for lung, and in most cases PCT and CRP examinations.

For the blood routine tests, the decreased PLT counts were observed in most cases, the median of PLT was $84 * 10^{9} / \mathrm{L}$ (range from $10-624 * 10^{9} / \mathrm{L}$ ). Only $3 \%(5 / 150)$ cases recorded higher WBC counts than $10 * 10^{9} / \mathrm{L}\left(\right.$ median $\left.=5.43 * 10^{9} / \mathrm{L}, 1.58-17.15 * 10^{9} / \mathrm{L}\right)$. However, $22 \%(33 / 150)$ cases were recorded lower WBC than $4^{\star} 10^{9} / \mathrm{L}$.

Mild liver injured were common for malaria patients. 13\%(20/150) cases had the ALT higher than $2 * U L N($ Upper limits of normal value, $37 \mathrm{U} / \mathrm{L}$ ). The values of ALT were range from $38 \mathrm{U} / \mathrm{L}$ with median of 9199 U/L. Hypoproteinemia were found in $31 \%(46 / 150)$ cases.

The bacterial infections was the major complication of the malaria patients. $20 \%(30 / 150)$ cases were diagnosed with bacterial infections. 97\%(29/30) infections were bacterial pneumonia(one case diagnosed with urinary tract infection). The diagnosis were established by CT scans or X-rays, manifestations, and other necessary examination.

The pathogen examination from blood found $5 \%(8 / 150)$ cases had higher infection rate for more than $5 \%$.

\section{Survival analysis for prolonged hospital stays}

The median length of stay(LOS) was 7 days, the range from 3-23 days. We used potential related factors to fit into a cox proportional hazard model to investigate the relevant factors and Hazard Ratios(HRs). The results were listed in Table 1. We defined the failure event as the discharge following advices(no patient discharge against advices), so that the HR value was the risk for discharge, that was, a risk factor for prolonged LOS if $\mathrm{HR}<1$.

In this study, pathogen type(dummy variables), bacterial infection, abnormal liver function, thrombocytopenia $\left(<100 * 10^{9} / \mathrm{L}\right)$, leukocytopenia $\left(<4.0 * 10^{9} / \mathrm{L}\right)$, anemia $(<120 \mathrm{~g} / \mathrm{L})$, jaundice $(\mathrm{TBIL}>$ $20 \mu \mathrm{mol} / \mathrm{L})$, high infection rate( $>5 \%)$, long $\operatorname{DOF}(>5$ days), misdiagnosis, hypoproteinemia(ALB $<35 \mathrm{~g} / \mathrm{L})$, PCT, and CRP were included in the full model of cox proportional hazard model.

By using stepwise variables selections, bacterial infection and low thrombocytopenia were found to be statistically significant in model. The hazard ratio were $0.58(p$-value $=0.01,95 \% \mathrm{Cl}=0.38-0.88)$ and 
$0.66(p$-value $=0.02,95 \% \mathrm{Cl}=0.47-0.94)$ respectively. The results were listed in Table 4 . The survival functions were plotted in Fig. 3 and Fig. 4.

Table 4

The results of cox proportional hazard model

\begin{tabular}{|lllllll|}
\hline Variables & HR & SE & z & $95 \% \mathbf{C l}$ & $p$-values \\
\hline Bacterial infection & 0.58 & 0.12 & -2.59 & 0.38 & 0.88 & 0.01 \\
P. falciparum infection solely & 4.93 & 2.62 & 3.00 & 1.74 & 13.98 & 0.00 \\
Leukopenia & 0.66 & 0.14 & -1.96 & 0.44 & 1.00 & 0.05 \\
Thrombopenia & 0.66 & 0.12 & -2.32 & 0.47 & 0.94 & 0.02 \\
\hline
\end{tabular}

Of note, according to our analysis, being infected by $P$. falciparum solely was the risk factor of discharge $(\mathrm{HR}=4.93,95 \% \mathrm{Cl}=1.74-14.00)$, that was, being infected by $P$. falciparum solely was the protective factor for prolonged hospital stays. This because of the differences of treatment scheme for pathogens. This was not the major topic of this paper, however, this factor remained in equation to balance the effects of different pathogens.

The results of log-rank test for survivor functions for bacterial infection and hypoproteinemia were statically significant, the $\chi^{2}$ values were $8.0(p$-value $=0.00)$ and $8.16(p$-value $=0.00)$ respectively. $($ Fig. 3,4$)$.

\section{Treatments and outcomes}

The imported cases of malaria had very low mortality which was reported as $0.5 \%(90 / 16733)^{1}$. In our study, all the patients were fulfilled the discharge criteria, no patient was dead. All the treatments were complied with national recommendation for malaria treatments(WS/T 485-2016) ${ }^{14}$.

\section{Discussion}

\section{Risk for post-elimination era in China}

The imported cases were the major risk for malaria in China post-elimination of malaria, especially imported $P$. falciparum. Malaria prevention activities should target exported labour groups given the increasing number of workers returning from overseas ${ }^{6}$. The major challenge is the unawareness of malaria for the doctors in primary medical care facilities ${ }^{15}$, the situation could be even worse postelimination. In our study, $17 \%(25 / 150)$ cases reported misdiagnosis by other medical facilities. However, we inputted this factor as an independent variable found it was not statistically significant by using cox proportional hazard model. We still not able to reject the negative impact for disease control due to the limitation of the dataset. This remind the continuous effects of training for doctors should not halt in post-elimination era. 


\section{Predictive factors for prolonged hospital stay}

Through cox proportional hazard model analysis, we found the low PLT count and complication of bacterial infection were the predictive factors for prolonged hospital stay. The two factors were protective for patients discharge, that were, the risk factors for prolonged hospital stays.

The prolonged hospital stays were implicated a more serious clinical situation, longer time would be taken to fulfill the discharge criteria. More medical resources would be consumed, and more local transmission risk existed. A previous study showed the PLT count predicted the severity of the disease ${ }^{16}$. Varadaraj had reported $97.6 \%(82 / 84)$ cases of malaria were found to be diagnosed with thrombocytopenia ${ }^{17}$.

Bacterial infection could be common in malaria patients ${ }^{18}$. A systematic review showed that $6.5 \%$ infection rate of bacterial was found in Africa Children with $P$. falciparum ${ }^{19}$. Of note, in our study, all the patients with bacterial infections were bacterial pneumonia and UTI, caused limited consequences after antibiotic treatments. There is still highly possible that blood stream infection occur, it may cause serious problems $^{20}$.

\section{Seasonal patterns of malaria}

We had the negative finding of the seasonality by using dataset of all the 150 cases admitted to our hospital during 2017-2020. However, the previous studies for malaria revealed that a seasonal pattern of incidence was found in Burundi ${ }^{21}$. Another study indicated seasonal transmission of malaria in Niger ${ }^{22}$. Mbouna found the seasonal relationships between climate, population density and malaria indicators in Cameroon ${ }^{23}$. According to our experience and statistical data analysis, we found no seasonality of the cases distributions. We thought the incidence of malaria in Africa could not directly affects the pattern of the exported labors returning, which was normally pre-planned. This finding implicated that hospitals should prepare the special wards regardless the seasonal variations of disease incidences in endemic area. Since in our hospital the wards for malaria patients were isolated from other diseases and equipped with mosquito repelling facilities to eliminate the possibility of local transmission.

\section{Clinical implications for geographical and pathogens distributions}

Understanding the geographical distributions of the pathogens plays pivotal roles for clinical diagnosis and treatments. Doctors could deduce the pathogens for patients judged by where they came from, without hours waiting for laboratory testing results for pathogens, giving the possibility of rapid access for treatment. A review confirmed that rapid access for treatment reduced risk of severe disease ${ }^{24,25}$. From our study, most cases came from Democratic Republic of the Congo(DRC), patients from DRC infected by almost all kinds of plasmodium. However, P.falciparum was the most common pathogen $(76 \%, 26 / 34)$. 


\section{Conclusions}

We had studies the epidemiological and clinical features of imported patients, which were the major risk for China in post elimination era. However, the misdiagnosis was common to see in our patients by other medical facilities, this reminds us continues effects must be taken. The thrombocytopenia and bacterial infection were the predictive factors for prolonged hospital. No seasonality was found for imported malaria patients.

\section{Abbreviations}

ALT, Alanine Aminotransferase; AST, Aspartate Aminotransferase PLT, Platelet; GLB, Globulin; ALB, Albumin; TBIL, Total Bilirubin WBC; White Blood Cell; SE, Standard Error; AUC, Area Under Curve; Cl, Confidential Interval; PCT, Procalcitonin; CRP, C-Reaction Protein; RDT, Rapid Diagnostic Tests

\section{Declarations}

\section{Funding}

This study was financially supported by 'Clinical assessments for improvement of Nonalcoholic steatohepatitis through Vitamin-D intermediated immune system and intestinal flora regulation(2020YFS0485)', which was granted by Department of Science and Technology of Sichuan Province. The funders had no role in study design, data collection and analysis, decision to publish, or preparation of the manuscript.

\section{Ethics approval and consent to participate}

Ethical approval for this study was obtained from the Ethics Committee of the Chengdu Public Health Clinical Center, and it was complied with the ethical guidelines of the Declaration of Helsinki 2008. The patient consents for inclusion was waived as the retrospective nature of this study.

\section{Competing interests}

The authors have no competing interests to declare.

\section{Authors contributions}

LH (Liang Huang), HJ (Hong Jin) and (Lin Wang) designed the study wrote manuscript, LH(Liang Huang) did data analysis. XXS(Xinxing Shi), XTK(Xintong Kang), HZ(Hong Zhang), and YLZ(Yilan Zeng) revised the manuscript. YL(Yang Liu) provided important ideas for study design. All authors have read and agreed to submit this manuscript.

\section{Conflict of interest}

The authors declare that they have no conflict of interest. 


\section{Consent for publication}

Not applicable

\section{Availability of data and materials}

The data supporting the findings of this study are available from the corresponding author LW on request.

\section{Acknowledgements}

We thank staff of No.3 Infectious Department of Chengdu Public Health Clinical Center for their hard working to fight against malaria.

\section{References}

1. Zhang, S.-S. et al. Imported malaria cases in former endemic and non-malaria endemic areas in China: are there differences in case profile and time to response? Infect. Dis. Poverty 8, 61 (2019).

2. Feng, J. et al. Ready for malaria elimination: zero indigenous case reported in the People's Republic of China. Malar. J. 17, 315 (2018).

3. Ding, C. et al. Malaria in China: a longitudinal population-based surveillance study. Epidemiol. Infect. 148, e37 (2020).

4. Li, X. H. et al. A Historical Review of WHO Certification of Malaria Elimination. Trends Parasitol. 35, 163-171 (2019).

5. Liu, Y. et al. Malaria in overseas labourers returning to China: an analysis of imported malaria in Jiangsu Province, 2001-2011. Malar. J. 13, 29 (2014).

6. Zhou, S. et al. Trends of imported malaria in China 2010-2014: analysis of surveillance data. Malar. J. 15, 39 (2016).

7. White, N. J. et al. Malaria. The Lancet 383, 723-735 (2014).

8. White, N. J. The Treatment of Malaria. N. Engl. J. Med. 335, 800-806 (1996).

9. National Health Commission: The standard malaria diagnosis. WS 259-2015(2016).

10. $R$ Core Team (2020). $R$ : A language and environment for statistical computing. $R$ Foundation for Statistical Computing, Vienna, Austria. URL https://www.R-project.org/.

11. Mark S. Pearce \& Richard Feltbower, 2005. 'SEAST: Stata module to calculate tests for seasonality with a variable population at risk,' Statistical Software Components S450001, Boston College Department of Economics.

12. J.J., A. networkD3:Creates 'D3' 'JavaScript' network, tree, dendrogram, and Sankey graphs from ' $R$ '.

13. Ling, X.-X. et al. Cost-effectiveness analysis of malaria rapid diagnostic tests: a systematic review. Infect. Dis. Poverty 8, 104 (2019).

14. National Health Commission: The standard of anti-malaria drug use. WS/T 485-2016. 
15. Wang, X.-L. et al. Management of imported malaria cases and healthcare institutions in central China, 2012-2017: application of decision tree analysis. Malar. J. 18, 429 (2019).

16. Gupta, P., Guddattu, V. \& Saravu, K. Characterization of platelet count and platelet indices and their potential role to predict severity in malaria. Pathog. Glob. Health 113, 86-93 (2019).

17. Varadaraj, S. L. G., Tripathy, G. C. N. \& Nithiya, D. R. Diagnostic Value of Low Platelets in Malaria. J. Assoc. Physicians India 67, 61-64 (2019).

18. Gloria P, ómez-P., Robin van, B., Martin P, G. \& Carlota, D. Plasmodium falciparum malaria and invasive bacterial co-infection in young African children: the dysfunctional spleen hypothesis. Malar J 2014 Aug 26.

19. Church, J. \& Maitland, K. Invasive bacterial co-infection in African children with Plasmodium falciparum malaria: a systematic review. BMC Med. 12, 31 (2014).

20. Mooney, J. P., Galloway, L. J. \& Riley, E. M. Malaria, anemia, and invasive bacterial disease: A neutrophil problem? J. Leukoc. Biol. 105, 645-655 (2019).

21. Moise, I., Roy, S., Nkengurutse, D. \& Ndikubagenzi, J. Seasonal and Geographic Variation of Pediatric Malaria in Burundi: 2011 to 2012. Int. J. Environ. Res. Public. Health 13, 425 (2016).

22. Guillebaud, J. et al. Epidemiology of malaria in an area of seasonal transmission in Niger and implications for the design of a seasonal malaria chemoprevention strategy. Malar. J. 12, 379 (2013).

23. Mbouna, A. D. et al. Modelled and observed mean and seasonal relationships between climate, population density and malaria indicators in Cameroon. Malar. J. 18, 359 (2019).

24. Mousa, A. et al. The impact of delayed treatment of uncomplicated P. falciparum malaria on progression to severe malaria: A systematic review and a pooled multicentre individual-patient metaanalysis. PLOS Med. 17, e1003359 (2020).

25. Tesfahunegn, A., Zenebe, D. \& Addisu, A. Determinants of malaria treatment delay in northwestern zone of Tigray region, Northern Ethiopia, 2018. Malar. J. 18, 358 (2019).

\section{Figures}




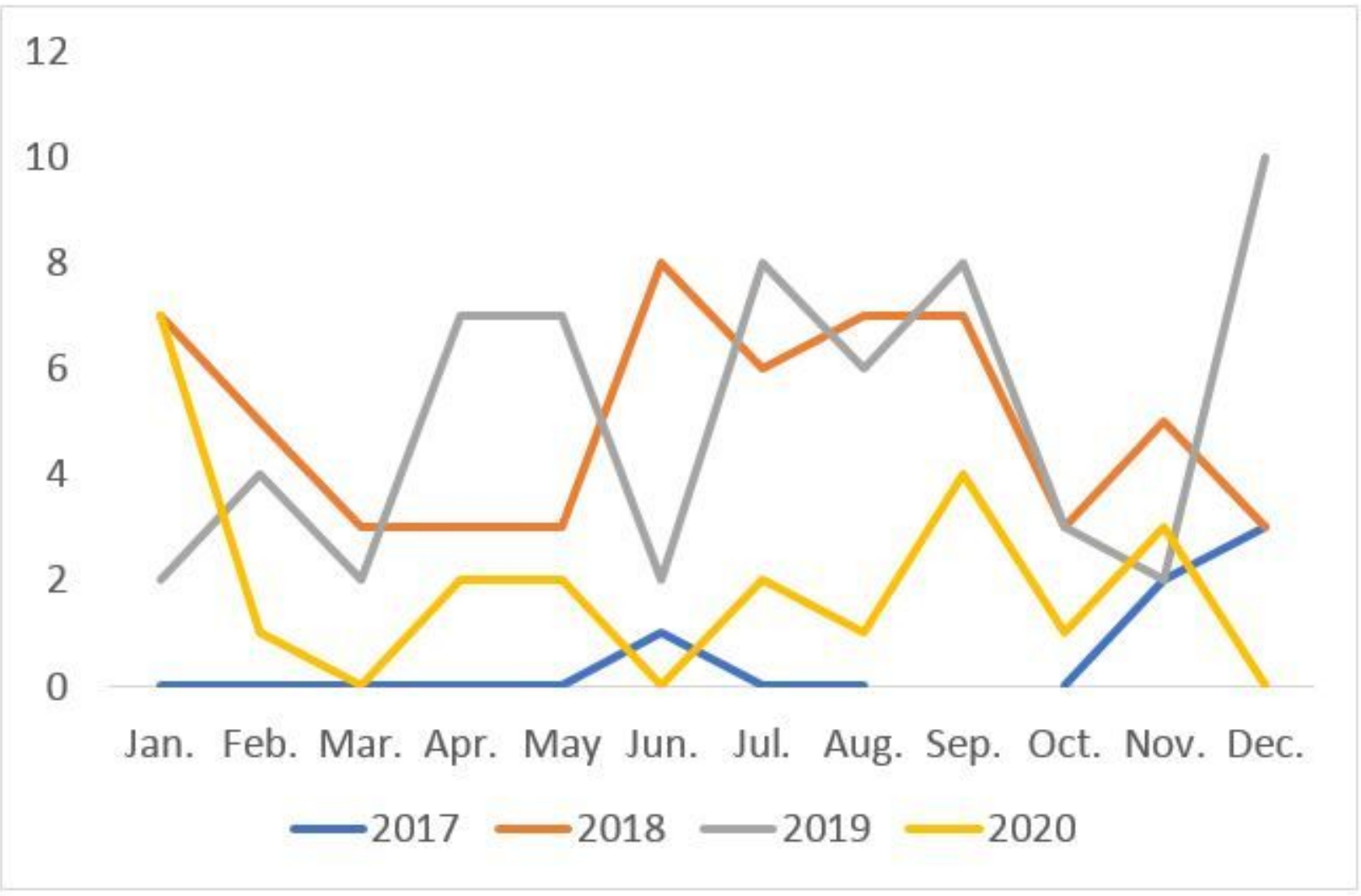

\section{Figure 1}

Time distribution of cases. X-axis is the months of cases admission time. Y-axis is the number of the cases. 


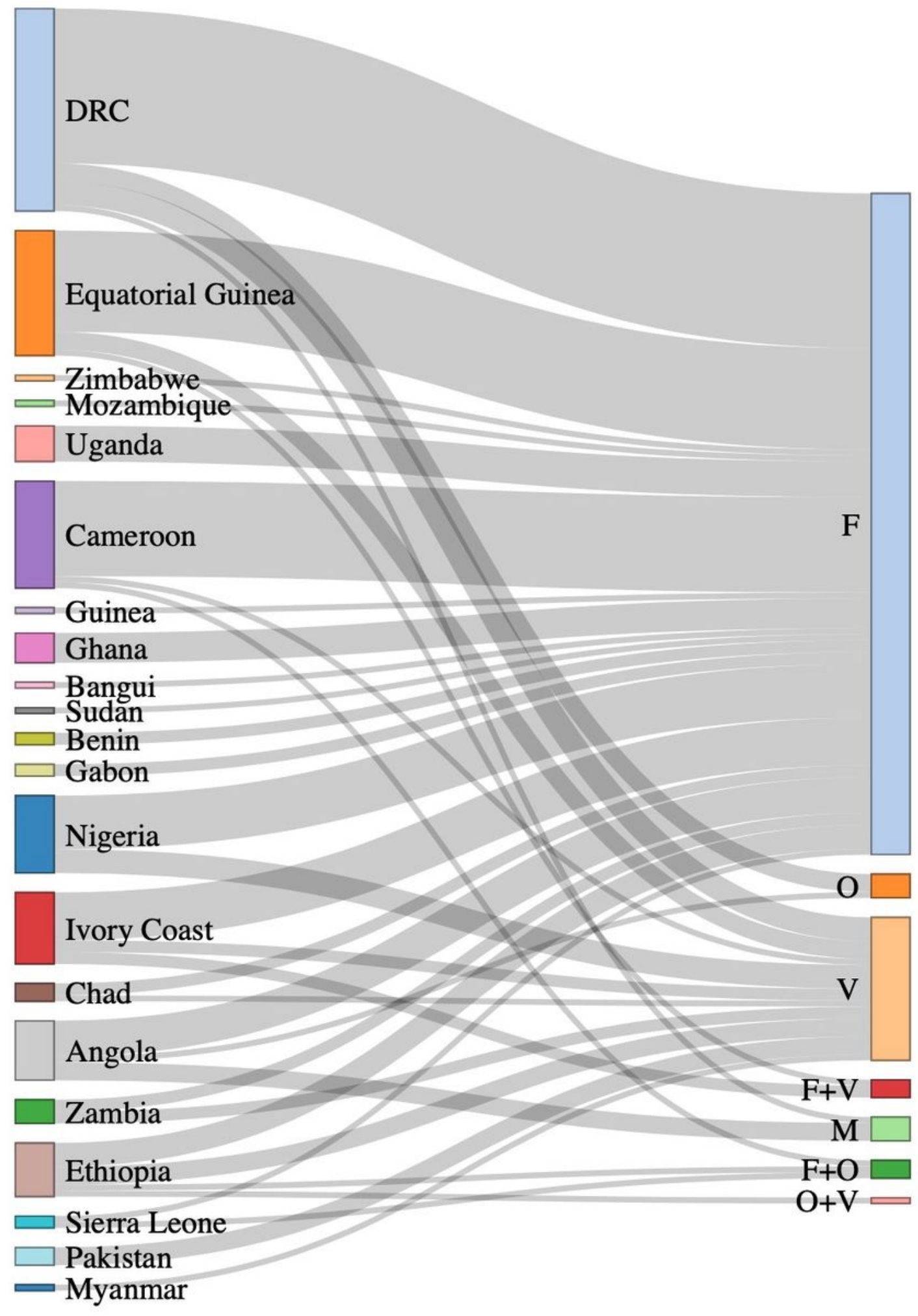

\section{Figure 2}

Geological and pathogen distributions F : P. falciparum. O: P. ovale. V: P. vivax. F+V: P. falciparum + P. vivax. M: P. malariae. F+O: P. falciparum + P. vivax. O+V: P. ovale + P. vivax. The interactive version of diagram deposits in : https://rpubs.com/hyuangx/sgview for open access. 


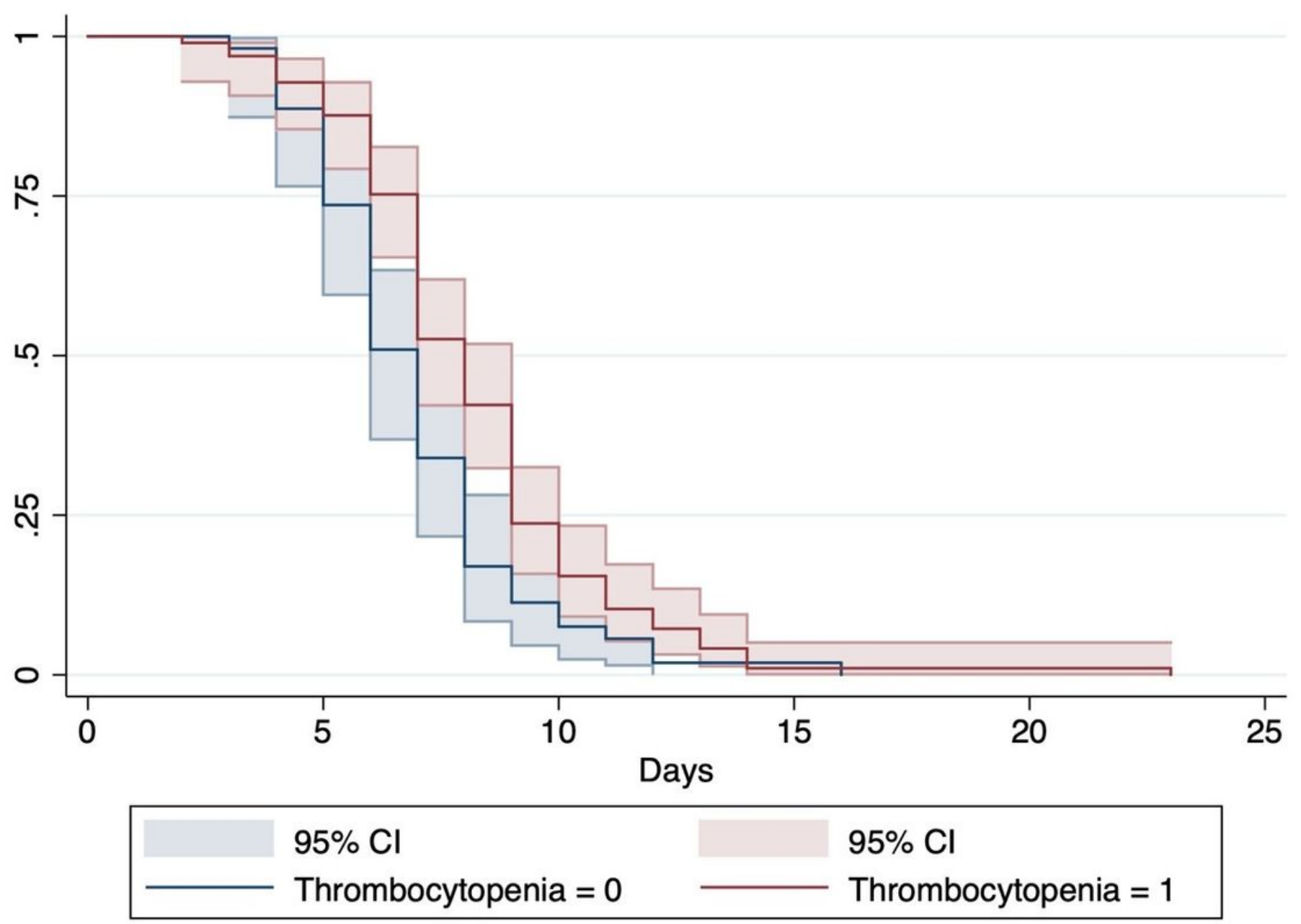

Figure 3

Survival functions for thrombocytopenia with $95 \%$ confidential interval. 


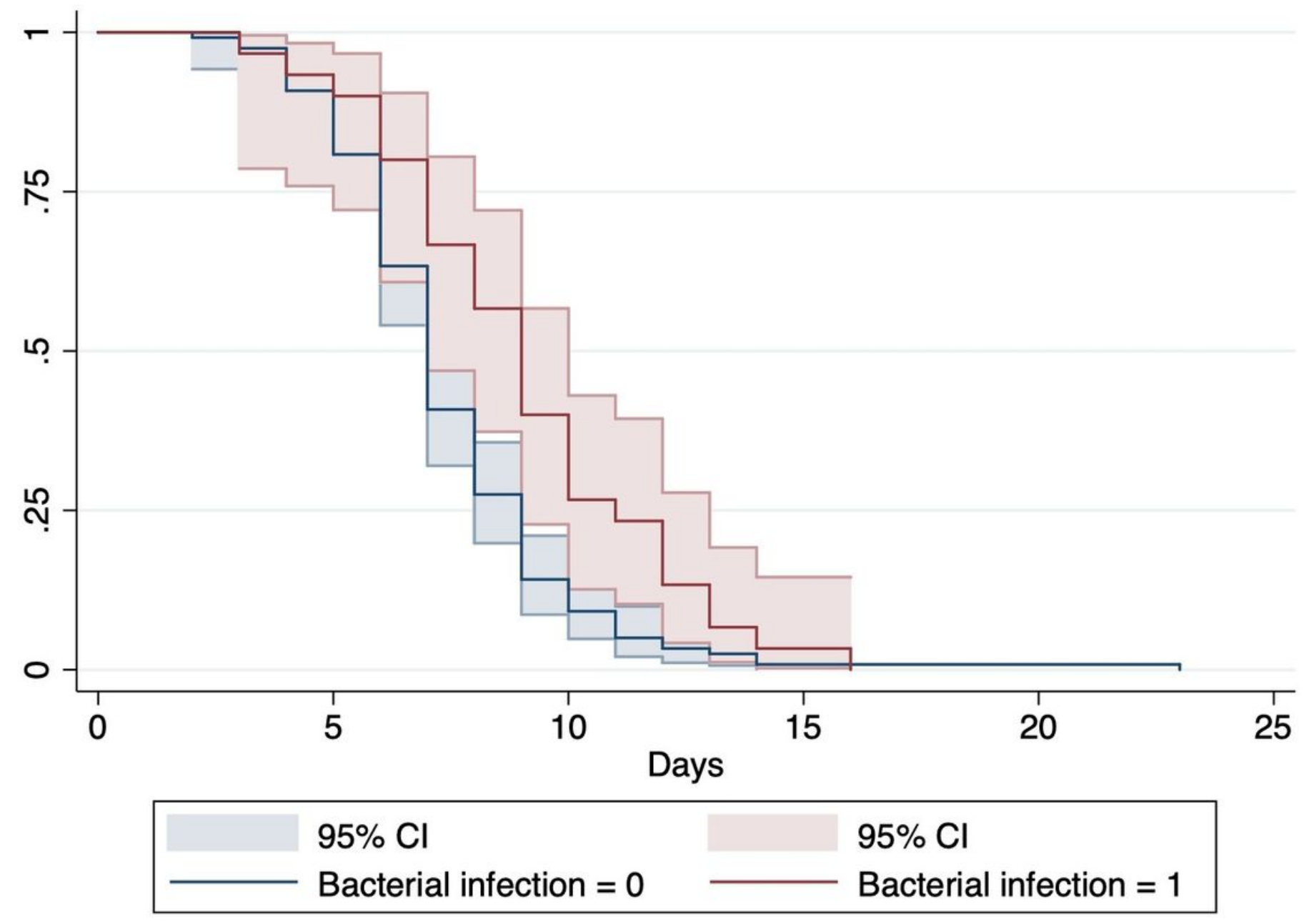

Figure 4

Survival functions for bacterial infection with $95 \%$ confidential interval. 